Canadian

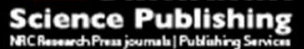

Canadian Journal of Civil Engineering Revue canadienne de génie civil

\title{
EFFECTIVENESS AND PERFORMANCE OF HIGH FRICTION SURFACE TREATMENTS AT A NATIONAL SCALE
}

\begin{tabular}{|r|l|}
\hline Journal: & Canadian Journal of Civil Engineering \\
\hline Manuscript ID & cjce-2016-0132.R1 \\
\hline Danuscript Type: & Article \\
\hline Complete List of Authors: & $\begin{array}{l}\text { Li, Qiang; Oklahoma State University, School of Civil \& Environmental } \\
\text { Engineering } \\
\text { Yang, Guangwei; Oklahoma State University Stillwater, Civil Engineering } \\
\text { Wang, Kelvin; Oklahoma State University, Civil Engineering } \\
\text { Zhan, You (Jason); Oklahoma State University Stillwater, Civil Engineering } \\
\text { Merritt, David; The Transtec Group, Inc. } \\
\text { Wang, Chaohui; Changl'an University, Highway Engineering }\end{array}$ \\
\hline Keyword: & $\begin{array}{l}\text { High Friction Surface Treatment (HFST), Friction Prediction, Multivariate } \\
\text { Analyses }\end{array}$ \\
\hline \multicolumn{2}{|c}{} \\
\hline
\end{tabular}




\section{EFFECTIVENESS AND PERFORMANCE OF HIGH FRICTION SURFACE}

\section{TREATMENTS AT A NATIONAL SCALE}

Qiang Joshua Li (Corresponding Author)

School of Civil and Environmental Engineering

Oklahoma State University, Stillwater, OK

qiang.li@okstate.edu

Telephone: 405-744-4638

Guangwei Yang

School of Civil and Environmental Engineering

Oklahoma State University, Stillwater, OK

Kelvin C.P. Wang

School of Civil and Environmental Engineering

Oklahoma State University, Stillwater, OK

You Zhan

School of Civil and Environmental Engineering

Oklahoma State University, Stillwater, OK

David Merritt

The Transtec Group, Inc., Austin, Texas

Chaohui Wang

School of Highway Engineering

Chang'an University, Xi'an, China

3,488 words +8 figures $(2,000$ words $)+3$ tables $(750$ words $)=6,238$ words 


\begin{abstract}
Although High Friction Surface Treatment (HFST) has been widely installed in recent years, validation efforts considering various materials, installation ages, environmental conditions, and traffic levels are missing primarily due to lacking of high-speed data collection instruments. Utilizing laser imaging technology and fixed-slip friction tester, this study collects comprehensive pavement surface data at 21 HFST sites in 11 states at highway speeds. Measurements on HFST and untreated pavements are compared to determine the effectiveness of HFST. Multivariate analyses are conducted to investigate the impacts of factors on HFST friction. Average temperature and installation age are identified as the significant factors. HFST sites constructed using calcined bauxite aggregates exhibit better friction performance than those using flints. Subsequently, friction models are developed to aid highway agencies in managing HFST.
\end{abstract}

Keywords: High Friction Surface Treatment (HFST), Effectiveness, Multivariate Analysis, Friction Models 


\section{INTRODUCTION}

High Friction Surfacing Treatments (HFST) were firstly applied in the United Kingdom in 1960s to maintain pavement skid resistance and reduce the fatalities and injuries from crashes that occur at or near horizontal curves (Brimley and Carlson 2012). Recently, the Federal Highway Administration (FHWA) Office of Pavement Technology has implemented the Surface Enhancements At Horizontal Curves program and Every Day Counts 2 program to install HFST at numerous horizontal curves throughout the U.S. due to higher friction demand of vehicles on curves and intersections than that on other pavement sections (The Trans Tec Group 2015). Through various HFST projects, the effectiveness of HFST in improving skid resistance and reducing crashes has been demonstrated (Bledsoe 2015, Moravec 2013, State of South Dakota Department of Transportation 2015, Bischoff 2008, Izeppi et al. 2010 and Waters 2011).

Generally pavement friction and macro-texture are tested before and after HFST installation to quantify the changes in surface skid resistance. Pavement friction is measured primarily using the Dynamic Friction Testers and agency-owned locked-wheel skid testers, while macro-texture is measured using stationary or low speed devices such as the Circular Track Meter, ASTM E 965 “Sand Patch” Method, or RoboTex (Moravec 2013 and Izeppi et al. 2010). Most of these devices require lane closure to perform the tests, and highway agencies must perform multiple data collection processes to gather different pavement surface characteristics. These limitations have constrained continuous evaluation of the surface characteristics of installed HFST sites in the longer term after they are opened to traffic. In addition, according to the authors' knowledge, no study has 
been conducted to evaluate HFST performance at a national scale under various traffic conditions, environments, and HFST materials.

This research applies the state-of-the-art 3D laser imaging based technology named PaveVision3D Ultra with necessary software tools for data collection and subsequent surface characterization for 21 HFST demonstration sites in 11 states as instructed by FHWA. The PaveVision3D Ultra system is capable of automatically conducting comprehensive pavement survey at full-lane coverage at $1 \mathrm{~mm}$ resolution in three dimensions at highway speed up to $60 \mathrm{mph}$, measuring pavement surface cracking, profiling, texture, geometric parameters, and reconstructing 3D virtual pavement (Wang 2011). This single-pass and complete lane coverage platform provides an ideal solution to evaluate the surface characteristics of HFST without interrupting traffic. In addition, pavement friction data on HFST is collected using the FHWA continuous fixed-slip friction tester, which uses a standardized smooth-tread test tire to measure friction in terms of a uniteless friction number, $\mathrm{Mu}$. Statistical data analysis is conducted to compare the measured surface characteristics before, after, and on the HFST to determine the effectiveness of the HFST. Multivariate analysis is included to identify the significant levels of potential influencing factors on HFST friction performance. Subsequently, pavement friction prediction models are developed for HFST.

\section{HFST DATA COLLECTION AND SURFACE CHARACTERIZATION}

\section{HFST Data Collection}

The data collection effort described herein includes testing of 21 HFST sites in 11 states as instructed by FHWA. The locations of the HFST sites are shown in FIG. 1. 
Considering the directions and number of lanes at each site, 41 data collections are conducted, with each PaveVision3D data collection covering a full traffic lane. With the exception of pavement friction data which are collected separately using FHWA's fixedslip friction tester, surface characteristics, including pavement rutting and macro-texture, are measured for each HFST site using the $1 \mathrm{~mm}$ PaveVision3D Ultra technology at posted highway speed without interfering the traffic. To determine the effectiveness of HFST in improving surface properties, all the data sets are collected beginning $300 \mathrm{ft}$ to $500 \mathrm{ft}$ before and through $300 \mathrm{ft}$ to $500 \mathrm{ft}$ after each HFST section.

\section{Pavement Rutting}

Rutting is defined as the permanent traffic-associated deformation within pavement layers. The recent provisionally-approved AASHTO Designation PP69-10 (AASHTO 2013) has been implemented into the PaveVision3D system for rutting characterization and cross slope measurements. Rutting in the left and right wheelpaths are averaged into average rutting in inches for each image frame with a dimension of $6.7 \mathrm{ft}(2,048 \mathrm{~mm})$ in length and $13.4 \mathrm{ft}(4,096 \mathrm{~mm})$ in width for each data collection. Rutting data are not calculated for rigid pavement sections, which are represented with zero rutting values.

\section{Pavement Friction}

Skid resistance is the ability of the pavement surface to prevent the loss of tire traction. The friction value from the HFST was reported every $1 \mathrm{ft}$ over the length of the section tested in order to show any variations in friction. Example friction data plots are shown in FIG. 2. Some sites show clear improvements of skid resistance (as shown in FIG. 2.a) and the differentiation of the HFST section from abutting pavement, while others don't 
show any trend (as shown in FIG. 2.b), in part because they are older HFST installations which may loss friction over time.

\section{Pavement Macro-texture}

The methodologies for texture measurement can be grouped into two categories: static and high-speed methods. Traditionally the measurement of pavement macro-texture at high-speed is based on single longitudinal or line-of-sight profile in the wheelpath. Mean Profile Depth (MPD) is one of the widely used texture indices. Example MPD data plots from the PaveVision3D Ultra system are shown in FIG. 3. Similar to friction data, some sites show much higher MPD values on HFST surface in contrast to the abutting pavement, while others don't show noticeable differences.

\section{EVALUATION OF HFST EFFECTIVENESS}

The $1 \mathrm{~mm} 3 \mathrm{D}$ data are collected $300 \mathrm{ft}$ to $500 \mathrm{ft}$ before and/or after each HFST section so that the measured surface characteristics before, after, and on the HFST sites can be compared and statistical analyses performed to determine the effectiveness of the HFST sites in improving surface characteristics. The beginning and end locations of each HFST section are determined based on "event markers" from the field friction data collection, and visually from collected 3D data sets. A paired t-test with equal variance is performed for each HFST site. The t-test investigates the difference between the means of the nonHFST and HFST treatment sections. At 95\% confidence interval, if P-value is smaller than 0.05 , the null hypothesis is rejected and the mean of the two groups are significantly different. 
The friction and MPD data are reported at $1.0 \mathrm{ft}$ interval. The t-test results for friction number and MPD for each data collection are summarized in Table 1. It is evident that HFST surfaces have significantly different friction numbers (with an average $\mathrm{P}=0.01$ for all the HFST sites) and surface texture MPD values (with an average $\mathrm{P}=$ 0.01 for all the HFST sites) than those on the abutting pavement. The average friction number of all HFST sites is 86.76 , while the friction of non-HFST surface has an average of 56.56. The average MPD of all HFST sites is 0.0522 inches $(1.32 \mathrm{~mm})$, while the MPD of non-HFST surface has an average of 0.0410 inches $(1.04 \mathrm{~mm})$.

FIG. 4 shows the difference between the two means of friction numbers and MPDs for each HFST data collection. The majority of the HFST sites have much larger friction numbers and MPD values comparing to the non-HFST surfaces. However, there are several exceptions. Sites 25 and 26 have smaller friction numbers on HFST surfaces than those on the non-HFST surfaces. The deicer materials observed on the two HFST locations during data collection may result in the lower friction numbers of the sites. Approximately identical friction numbers are observed for Site 15 on HFST and nonHFST surfaces. In addition, the friction on HFST of Site 30 is slightly higher than that on the non-HFST surface even though the treatment was applied only one year prior to data collection. For MPD, 5 out of 41 collections report smaller MPDs on HFST surfaces, such sections including Sites 3, 4, 22, 23, and 24 .

The comparisons of the average rutting on HFST and non-HFST of asphalt pavement surfaces are shown in FIG. 5. No consistent statistical conclusion can be made based on the t-test results: some sections have significantly different rutting while others 
don't between HFST and non-HFST segments. This is logical since HFST treatments do not correct rutting problems on existing pavement surfaces. The rutting on an HFST surface is dependent on the pavement condition before the treatment. The average rutting are $4.24 \mathrm{~mm}$ and $4.53 \mathrm{~mm}$ for HFST and non-HFST respectively. The average P-value is 0.14 , which indicates that on average no significant difference is observed for rutting on non-HFST versus HFST surfaces.

\section{HFST FRICTION PERFORMANCE}

\section{Potential Influencing Factors}

Influencing factors relating to pavement friction are generally categorized as pavement surface characteristics, vehicle operational parameters, tire properties, and environmental factors (Hall et al. 2009). The influence of asphalt mixture type and Portland cement concrete surface textures on pavement friction has been widely researched (Asi 2007, Ahammed and Tighe 2008). Several pavement friction models has been developed, some of which are established based on macro- and micro-texture of mix aggregates (Ergun et al. 2005). Operational factors including water film thickness, test speed, or temperature are found to affect friction measurement (Flintsch et al. 2012 and Henry 2000). Studies also find that temperature could affect pavement friction in short-term and long-term (Ahammed and Tighe 2010, Luo 2003, and Fuents 2009).

Based on data availability in this study, precipitation, average temperature, HFST installation age, aggregate type, and annual average daily traffic (AADT) for each HFST site are identified as the potential influencing factors to evaluate the HFST friction performance in the long-term and at a wider scale. Precipitation and average temperature 
data are obtained from the climate station close to each HFST site. Two indicators, friction number on HFST (FN $\mathrm{HFST}_{\mathrm{H}}$ ) and the ratio of friction number (FN Ratio) are used to evaluate HFST pavement friction performance. Herein, FN Ratio is the friction number

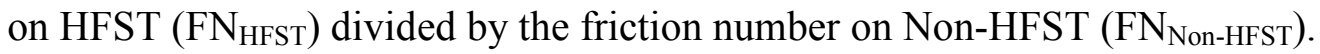

$$
\text { FN Ratio }=\frac{F N_{H F S T}}{F N_{N O n-H F S T}}
$$

The potential influencing factors and corresponding friction information for each data collection are provided in Table 2. FN Ratio, $\mathrm{FN}_{\mathrm{HFST}}$, and $\mathrm{FN}_{\mathrm{Non} \text {-HFST }}$ for each data collection are evaluated considering the aforementioned factors:

- As shown in FIG. 6, FN Ratio and FN $\mathrm{F}_{\mathrm{HFST}}$ show decreasing trends with the increase of HFST installation age and average temperature.

- For HFST sites with more than 60 month of installation age, FN Ratio in FIG. 6(b) approaches approximately 1.0, which indicates that the average life of a HFST surface is around 5 years and the benefit of HFST in friction effectiveness is nearly lost by that time.

- HFST sites installed with calcined bauxite aggregates exhibit better friction performance than those with flints (FIG. 7).

- No trend is observed between friction performance (FN Ratio and $\mathrm{FN}_{\mathrm{HFST}}$ ) and precipitation, AADT respectively, neither does the accumulated traffic volume (which is AADT times 365 days and HFST installation age).

- There is no obvious relationship between $\mathrm{FN}_{\mathrm{Non}-\mathrm{HFST}}$ and the five influencing factors. 
Even though HFST sections in colder regions experience more frequent snow plowing and deicing activities, it demonstrates that the effect of winter maintenance on HFST performance has been minimal. On the contrary, higher temperature seems to cause a softening effect on the HFST resin and possibly the underlying asphalt binder, which would allow HFST aggregate to penetrate into the softened surface with reduced macro-texture or lead to the loss of aggregate due to reduced bonding strength. As a result, lower FN Ratio and $\mathrm{FN}_{\mathrm{HFST}}$ are measured on HFST sections in warmer regions. In addition, HFST is subject to deterioration through climate and traffic wear, and therefore older HFST sections show lower FN Ratio and FN $N_{H F S T}$.

Intuitively, AADT should have an impact on pavement friction development since pavement wears and friction values decrease with repetitive traffic applications. However, majority of the HFST sites are located either on ramps or multiple-lane highways. Detailed traffic data on ramps and for each lane of multiple-lane sections are not available and the AADT values have to be estimated based on engineering judgment. With more accurate traffic data, the relationship between AADT and friction may be better revealed. It should also be noted that only one data collection was performed for each HFST site and no time-series comparisons are available for each site. Most sites on ramps are older in age but with much lower estimated AADT values, while sites on mainline highways are younger in age but with higher traffic volumes. As a result, the accumulated traffic volumes of HFST sites on ramps are less than that of the sites installed more recently on mainline roads. Therefore, the friction number does not decrease with the increase of accumulated traffic volume if various levels of traffic 
volumes on all the tested HFST sites are considered simultaneously in the analysis. When time-series data are available, the deterioration of friction for each site should be noticeable as the site ages and carries more accumulate traffic.

\section{Multivariate Analysis Results}

Multivariate analysis is conducted to analyze the effect of the influencing variables on FN Ratio, FN $\mathrm{FFST}_{\mathrm{HF}}$, and $\mathrm{FN}_{\mathrm{Non}-\mathrm{HFST}}$. Precipitation, average temperature, HFST installation age, AADT are continuous independent variables, while aggregate type is a categorical variable and should be properly coded and quantified before multivariate analysis could be performed. Herein bauxite aggregate is represented as ' 1 ' while flint is coded as ' 0 ' in data preparation of model development. P-value is used to evaluate the significant level of each influencing variable on the dependent outcomes (which are the two friction performance measures). The multivariate analysis result is shown in Table 3.

At $95 \%$ confidence interval, if P-value is smaller than 0.05 , the corresponding variable has significant effect on the dependent variables. The P-values for average temperature and HFST installation age are much smaller than 0.05 , which means they have significant effect on FN Ratio and $\mathrm{FN}_{\mathrm{HFST}}$. The corresponding coefficient of those two dependent variables are negative, which indicates that FN Ratio and $\mathrm{FN}_{\mathrm{HFST}}$ decrease as those two variables increase. P-value of aggregate type (larger than 0.05) shows that it is not a significant factor for FN Ratio and $\mathrm{FN}_{\mathrm{HFST}}$. However the corresponding coefficients of aggregate type are positive, which implies HFST using bauxite (coded as '1') will add a positive number into the predicted FN Ratio or FN $\mathrm{HFST}_{\mathrm{H}}$ while HFST using flint (coded as ' 0 ') doesn't include such positive contribution to friction numbers. This 
statistic results support the data shown in FIG. 7 that FN Ratio and FN $\mathrm{HFST}_{\mathrm{H}}$ for HFST using bauxite are generally greater than those using flint. For $\mathrm{FN}_{\text {Non-HFST, }} \mathrm{P}$-values for all the five variables are greater than 0.05 , which indicates that the independent variables have insignificant impacts on pavement friction for non-HFST sections.

Subsequently, multivariate analysis considering only the two significant influencing factors (average temperature and installation age) is conducted and the results are appended in Table 3. Both factors remain to be significant for the prediction of FN Ratio. However, the P-value of average temperature on $\mathrm{FN}_{\mathrm{HFST}}$ is larger than 0.05 , which indicates that the impact of average temperature on $\mathrm{FN}_{\mathrm{HFST}}$ is not as significant as that of installation age, which supports the data shown in FIG. 6(c) that $\mathrm{FN}_{\mathrm{HFST}}$ decreasing trend is not as significant as that of installation age. The multiple linear regression models are therefore developed as shown in Equation (2) to predict FN Ratio and $\mathrm{FN}_{\mathrm{HFST}}$ :

$$
\begin{aligned}
& F N \text { Ratio }=2.912-0.019 * \text { Average Temperature }-0.013 * \text { Age } \\
& F N_{H F S T}=130.027-0.507 * \text { Average Temperature }-0.575 * \text { Age }
\end{aligned}
$$

The predicted and measured FN Ratio and $\mathrm{FN}_{\mathrm{HFST}}$ for all the 41 data collections are plotted in FIG. 8. The predictions follow similar development trend as the actual measured FN Ratio and $\mathrm{FN}_{\mathrm{HFST}}$, and the R-squared values are 0.55 and 0.50 respectively. There are several potential reasons may cause the moderate R-squared values. Several factors of many HFST sites may take the same values, which reduces the variability of the data sets. For example, if HFST sites are close to each other in distance, the climate data for these sites are obtained from one weather station and the same values of precipitation and average temperature are used. For HFST sites with multiple lanes, 
AADT data remains the same for the site for all lanes. More detailed and accurate data could result in better friction prediction models with higher R-squared values.

\section{CONCLUSIONS}

This project applies the 3D laser imaging based PaveVision3D Ultra technology with necessary software tools for data collection and subsequent surface characterization and evaluation of the HFST demonstration sites. The 1mm 3D data for 21 HFST sites in 11 states with a total of 41 sections are collected for each traffic lane at the posted highway speeds. Pavement rutting and macro-texture data are calculated from collected $1 \mathrm{~mm} 3 \mathrm{D}$ data sets, while pavement friction data are collected using FHWA's continuous fixed-slip friction tester.

The measured surface characteristics on the HFST sites and untreated existing pavements are compared and paired t-tests are performed to determine the effectiveness of the HFST sites in improving surface characteristics. Strong evidence is found that the HFST surfaces have statistically significant higher friction numbers and surface macrotexture MPD values than those on the adjacent pavements without HFST. There exist several exceptions to such trend, 2 sections for friction data and 5 sections for MPD data, probably due to the long installation age and use of winter maintenance. Subsequently, multivariate analysis are conducted to investigate the impacts of five independent variables: precipitation, average temperature, HFST installation age, aggregate type, and AADT, on HFST friction performance. Average temperature and HFST installation age are identified to have significantly impact on friction number on HFST (FN $\mathrm{HFST})$ and the ratio of friction on HFST to that on non-HFST (FN Ratio). Based on the trend between 
FN Ratio and installation age, the benefit of HFST in friction effectiveness is lost after approximate 60 months (5 years) of service. HFST sites using calcined bauxite aggregates exhibit higher friction performance than those using flints. The regressional friction prediction models are therefore developed for HFST, which can be used to predict the service life of HFST installation and aid decision making within a highway agency. However, it should be noted that the models don't consider the pavement conditions before HFST application and HFST construction quality variations as the dependent variables due to the unavailability of data. In addition, detailed traffic data for ramps and each lane of sites with multiple lanes are not available and have to be estimated during the model development.

\section{ACKNOWLEDGEMENTS}

This paper was prepared under research project, “3D Laser Imaging based Real Time Pavement Surface Evaluation for High Friction Surfacing Treatments (HFST)”, sponsored by the Federal Highway Administration (FHWA). The author would like to thank Mr. Justin Thweatt and Mr. Rob Whirledge for collecting filed data for this project. The opinions expressed in the paper are those of the authors, who are responsible for the accuracy of the facts and data herein, and do not necessarily reflect the official policies of the sponsoring agencies. This paper does not constitute a standard, regulation, or specification.

\section{References}

AASTHO. 2013. Standard Practice for Determining Pavement Deformation Parameters and Cross Slope from Collected Transverse Profiles. AASHTO Designation: PP69- 
10. American Association of State Highway and Transportation Officials. Washington, D.C.

Ahammed M.A. and Tighe S.L. 2008. Concrete Pavement Surface Textures and Multivariables Frictional Performance Analysis: a North American Case Study. Canadian Journal of Civil Engineering, 35(7): 727-738.

Ahammed M.A. and Tighe S.L. 2010. Effect of Short-term and Long-term Weather on Pavement Surface Friction. International Journal of Pavement Research and Technology, 3(6): 295-302.

Asi I. M. 2007. Evaluating Skid Resistance of Different Asphalt Concrete Mixes. Building and Environment, 42: 325-329.

Bledsoe J. 2015. Missouri Demonstration Project: The Use of High-Friction Surface Treatments on Missouri Highways. FHWA, U.S. Department of Transportation. Available from http://plan4operations.dot.gov/hfl/summary/pdf_2/Missouri $\% 20$ High $\% 20$ Friction $\% 2$ 0Report $\% 20 \mathrm{draft} \% 20$ Final.pdf [accessed 30 June 2015].

Bischoff D. 2008. Investigative Study of the Italgrip ${ }^{\text {TM }}$ System. WI-04-08. Wisconsin Department of Transportation, Madison, WI. Available from http://wisdotresearch.wi.gov/wp-content/uploads/wi-04-08italgrip.pdf [accessed 20 June 2015].

Brimley B. and Carlson P. 2012. Using High Friction Surface Treatments to Improve Safety at Horizontal Curves. Texas Transportation Institute. Available from 
http://d2dt15nnlpfr0r.cloudfront.net/tti.tamu.edu/documents/TTI-2012-8.pdf

[accessed 25 June 2015].

Ergun M., Iyinam S., and Iyinam A.F. 2005. Prediction of Road Surface Friction

Coefficient Using Only Macro- and Microtexture Measurements. Journal of Transportation Engineering, 131(4): 311-319.

Flintsch G.W. et al. 2012. The Little Book of Tire Pavement Friction. Pavement Surface Properties Consortium. Available from https://secure.hosting.vt.edu/www.apps.vtti.vt.edu/1pagers/CSTI_Flintsch/The\%20Little\%20Book\%20of\%20Tire\%20Pavement $\% 20$ Fric tion.pdf [accessed 1 May 2015].

Fuents L. G. 2009. Investigation of the Factors Influencing Skid Resistance and the International Friction Index. PhD. Thesis, University of South Florida, Tampa, FL.

Hall J. W. et al. 2009. NCHRP Web Document 108: Guide for Pavement Friction. TRB, National Research Council, Washington, D.C. Available from http://onlinepubs.trb.org/onlinepubs/nchrp/nchrp_w108.pdf [accessed 14 May 2015].

Henry, J. J. 2000. NCHRP Synthesis 291: Evaluation of Pavement Friction Characteristics. TRB, National Research Council, Washington, D.C.

Izeppi E., Flintsch G. and McGhee K. 2010. Field Performance of High Friction Surfaces. Publication FHWA/VTRC 10-CR6. FHWA, U.S. Department of Transportation. Available from 
http://www.virginiadot.org/vtrc/main/online_reports/pdf/10-cr6.pdf [accessed 15

June 2015].

Luo Y. 2003. Effect of Pavement Temperature on Frictional Properties of Hot-MixAsphalt Pavement Surfaces at the Virginia Smart Road. M.S. Thesis, Virginia Polytechnic Institute and State University, Blacksburg, Va.

Moravec M. 2013. High Friction Surface Treatments at High-Crash Horizontal Curves. Arizona Pavements/Materials Conference, Phoenix, AZ. Available from http://www.intrans.iastate.edu/events/midcon2013/documents/presentationsubmissions/3-C 61_08142013.pdf [accessed 30 June 2015].

South Dakota Department of Transportation (SDDOT). 2015. Accelerated Innovation Deployment (AID) Demonstration Project: High Friction Surface Treatment. Available from http://www.fhwa.dot.gov/accelerating/grants/pdfs/SD_2014_AID_Grant.pdf [accessed 11 June 2015]

The Trans Tec Group, INC. 2015. Welcome to High Friction Roads. Available from http://www.highfrictionroads.com [accessed 25 June 2015]

Wang Kelvin C. P. 2011. Elements of Automated Survey of Pavements and a 3D Methodology. Journal of Modern Transportation, 19(1): 51-57.

Waters J. 2011. High Friction Surfacing Failure Mechanisms. $3^{\text {rd }}$ International Surface Friction Conference, Safer Road Surfaces - Saving Lives, Gold Coast, Australia. 


\section{LIST OF TABLES}

Table 1. Paired T-Test Results for Friction Numbers and MPDs

Table 2. Potential Influencing Factors of HFST Friction Performance

Table 3. Multivariate Analysis Results 
Table 1. Paired T-Test Results for Friction Numbers and MPDs

\begin{tabular}{|c|c|c|c|c|c|c|c|c|c|c|}
\hline \multirow{2}{*}{$\begin{array}{c}\text { Data } \\
\text { Collection } \\
\text { ID }\end{array}$} & \multicolumn{5}{|c|}{ Friction Number } & \multicolumn{5}{|c|}{ MPD (Inch) } \\
\hline & $\begin{array}{l}\text { Mean - } \\
\text { HFST }\end{array}$ & $\begin{array}{c}\text { Mean - Non } \\
\text { HFST }\end{array}$ & $\mathrm{df}$ & $\begin{array}{c}P \\
\text { value }\end{array}$ & $\begin{array}{l}\text { Sig. } \\
\text { Diff? }\end{array}$ & $\begin{array}{l}\text { Mean - } \\
\text { HFST }\end{array}$ & $\begin{array}{c}\text { Mean - Non } \\
\text { HFST }\end{array}$ & $\mathrm{df}$ & $\begin{array}{c}\mathrm{P} \\
\text { value }\end{array}$ & $\begin{array}{c}\text { Sig. } \\
\text { Diff? }\end{array}$ \\
\hline 1 & 98.08 & 51.79 & 1060 & 0 & Yes & 0.0498 & 0.0345 & 1274 & 0 & Yes \\
\hline 2 & 103.49 & 58.04 & 990 & 0 & Yes & 0.0514 & 0.0284 & 1172 & 0 & Yes \\
\hline 3 & 87.89 & 68.3 & 1540 & 0 & Yes & 0.0548 & 0.0677 & 1739 & 0 & Yes \\
\hline 4 & 81.69 & 70.38 & 1541 & 0 & Yes & 0.0526 & 0.0581 & 991 & 0 & Yes \\
\hline 5 & 107.86 & 63.86 & 1477 & 0 & Yes & 0.0625 & 0.0465 & 1184 & 0 & Yes \\
\hline 6 & 112.42 & 63.85 & 1499 & 0 & Yes & 0.0634 & 0.0459 & 957 & 0 & Yes \\
\hline 7 & 104.05 & 60.55 & 1088 & 0 & Yes & 0.0513 & 0.0342 & 978 & 0 & Yes \\
\hline 8 & 98.74 & 57.76 & 984 & 0 & Yes & 0.0497 & 0.0321 & 1454 & 0 & Yes \\
\hline 9 & 100.6 & 55.84 & 1113 & 0 & Yes & 0.0517 & 0.0346 & 1075 & 0 & Yes \\
\hline 10 & 91.35 & 44.1 & 826 & 0 & Yes & 0.0501 & 0.03 & 691 & 0 & Yes \\
\hline 11 & 102.39 & 61.77 & 1019 & 0 & Yes & 0.049 & 0.036 & 1243 & 0 & Yes \\
\hline 12 & 94.59 & 49.12 & 1194 & 0 & Yes & 0.0496 & 0.0351 & 1119 & 0 & Yes \\
\hline 13 & 57.64 & 43.83 & 1272 & 0 & Yes & 0.0383 & 0.0283 & 1132 & 0 & Yes \\
\hline 14 & 83.17 & 52.64 & 768 & 0 & Yes & 0.043 & 0.0192 & 285 & 0 & Yes \\
\hline 15 & 65.55 & 64.93 & 925 & 0.38 & No & 0.0362 & 0.0217 & 351 & 0 & Yes \\
\hline 16 & 64.28 & 53.3 & 1677 & 0 & Yes & 0.0456 & 0.0332 & 1600 & 0 & Yes \\
\hline 17 & 59.14 & 52.73 & 1767 & 0 & Yes & 0.0291 & 0.0289 & 2143 & 0.41 & No \\
\hline 18 & 73.12 & 54.51 & 831 & 0 & Yes & 0.0419 & 0.0313 & 616 & 0 & Yes \\
\hline 19 & 94.98 & 60.43 & 791 & 0 & Yes & 0.09 & 0.0825 & 1181 & 0.03 & Yes \\
\hline 20 & 72.81 & 54.5 & 471 & 0 & Yes & 0.0351 & 0.0323 & 645 & 0 & Yes \\
\hline 21 & 68.93 & 54.32 & 367 & 0 & Yes & 0.0397 & 0.0257 & 418 & 0 & Yes \\
\hline 22 & 64.49 & 45.09 & 244 & 0 & Yes & 0.0423 & 0.0812 & 303 & 0 & Yes \\
\hline 23 & 64.14 & 37.95 & 253 & 0 & Yes & 0.0539 & 0.1083 & 365 & 0 & Yes \\
\hline 24 & 84.14 & 76.23 & 524 & 0 & Yes & 0.0384 & 0.0498 & 399 & 0 & Yes \\
\hline 25 & 52.1 & 69.09 & 1940 & 0 & Yes & 0.041 & 0.0356 & 1308 & 0 & Yes \\
\hline 26 & 56.5 & 76.24 & 1995 & 0 & Yes & 0.038 & 0.0383 & 1814 & 0.01 & Yes \\
\hline 27 & 74.62 & 60.83 & 900 & 0 & Yes & 0.0548 & 0.0449 & 844 & 0 & Yes \\
\hline 28 & 72.79 & 55.66 & 267 & 0 & Yes & 0.0562 & 0.0402 & 859 & 0 & Yes \\
\hline 29 & 101.45 & 66.22 & 310 & 0 & Yes & 0.0579 & 0.0465 & 429 & 0 & Yes \\
\hline 30 & 59.5 & 55.74 & 414 & 0 & Yes & 0.0548 & 0.0514 & 769 & 0 & Yes \\
\hline 31 & 90.25 & 41.1 & 2543 & 0 & Yes & 0.0572 & 0.0293 & 2100 & 0 & Yes \\
\hline 32 & 93.37 & 42.45 & 2561 & 0 & Yes & 0.0581 & 0.027 & 1981 & 0 & Yes \\
\hline 33 & 107.81 & 53.06 & 1968 & 0 & Yes & 0.0592 & 0.0313 & 588 & 0 & Yes \\
\hline 34 & 108.33 & 55.36 & 1734 & 0 & Yes & 0.0734 & 0.0382 & 1376 & 0 & Yes \\
\hline 35 & 102.6 & 57.24 & 1069 & 0 & Yes & 0.0671 & 0.0452 & 1306 & 0 & Yes \\
\hline 36 & 92.68 & 49.37 & 1635 & 0 & Yes & 0.0526 & 0.0397 & 1286 & 0 & Yes \\
\hline 37 & 111.46 & 51.08 & 1468 & 0 & Yes & 0.0474 & 0.035 & 489 & 0 & Yes \\
\hline 38 & 97.06 & 54.02 & 969 & 0 & Yes & 0.0692 & 0.0354 & 1803 & 0 & Yes \\
\hline 39 & 124.28 & 50.44 & 1962 & 0 & Yes & 0.0588 & 0.0354 & 1840 & 0 & Yes \\
\hline 40 & 88.41 & 58.68 & 1864 & 0 & Yes & 0.0608 & 0.0381 & 1054 & 0 & Yes \\
\hline 41 & 88.32 & 66.57 & 1369 & 0 & Yes & 0.0663 & 0.0419 & 989 & 0 & Yes \\
\hline
\end{tabular}


Table 2. Potential Influencing Factors of HFST Friction Performance

\begin{tabular}{|c|c|c|c|c|c|c|c|c|c|}
\hline ID & $\begin{array}{l}\text { Precipitation } \\
\text { (Inch) }\end{array}$ & $\begin{array}{c}\text { Air } \\
\text { Temperature } \\
\left({ }^{\circ} \mathrm{F}\right) \\
\end{array}$ & $\begin{array}{c}\text { Data } \\
\text { Collection } \\
\text { Speed (MPH) }\end{array}$ & $\begin{array}{c}\text { Installation } \\
\text { Age } \\
\text { (Month) } \\
\end{array}$ & Aggregate & AADT & $\mathrm{FN}_{\mathrm{HFST}}$ & $\mathrm{FN}_{\text {Non-HFST }}$ & $\begin{array}{c}\text { FN } \\
\text { Ratio }\end{array}$ \\
\hline 1 & 34.6 & 51.3 & 40 & 30 & Bauxite & 14167 & 104.05 & 60.55 & 1.72 \\
\hline 2 & 34.6 & 51.8 & 40 & 30 & Bauxite & 14167 & 98.74 & 57.76 & 1.71 \\
\hline 3 & 34.6 & 51.9 & 40 & 30 & Bauxite & 14167 & 100.6 & 55.84 & 1.8 \\
\hline 4 & 34.6 & 51.4 & 40 & 30 & Bauxite & 14167 & 91.35 & 44.1 & 2.07 \\
\hline 5 & 34.6 & 52.3 & 40 & 30 & Bauxite & 14167 & 102.39 & 61.77 & 1.66 \\
\hline 6 & 34.6 & 51.8 & 40 & 30 & Bauxite & 14167 & 94.59 & 49.12 & 1.93 \\
\hline 7 & 37.7 & 86.2 & 40 & 30 & Bauxite & 13500 & 87.89 & 68.3 & 1.29 \\
\hline 8 & 37.7 & 85.2 & 40 & 30 & Bauxite & 13500 & 81.69 & 70.38 & 1.16 \\
\hline 9 & 12.8 & 38.5 & 30 & 63 & Flint & 2760 & 84.14 & 76.23 & 1.1 \\
\hline 10 & 14 & 39 & 40 & 63 & Flint & 5955 & 52.1 & 69.09 & 0.75 \\
\hline 11 & 14 & 38.5 & 40 & 63 & Flint & 5955 & 56.5 & 76.24 & 0.74 \\
\hline 12 & 35.5 & 33.9 & 40 & 64 & Flint & 26165 & 57.64 & 43.83 & 1.32 \\
\hline 13 & 35.5 & 33.7 & 30 & 64 & Flint & 1717 & 83.17 & 52.64 & 1.58 \\
\hline 14 & 35.5 & 33.8 & 30 & 64 & Flint & 1717 & 65.55 & 64.93 & 1.01 \\
\hline 15 & 34.3 & 36.5 & 40 & 64 & Flint & 6350 & 64.28 & 53.3 & 1.21 \\
\hline 16 & 27.2 & 50 & 40 & 4 & Bauxite & 400 & 102.6 & 57.24 & 1.79 \\
\hline 17 & 27.2 & 50.9 & 40 & 4 & Bauxite & 400 & 92.68 & 49.37 & 1.88 \\
\hline 18 & 27.2 & 50.7 & 40 & 4 & Bauxite & 400 & 111.46 & 51.08 & 2.18 \\
\hline 19 & 27.2 & 37.5 & 40 & 4 & Bauxite & 1720 & 97.06 & 54.02 & 1.8 \\
\hline 20 & 27.2 & 37.8 & 40 & 4 & Bauxite & 1720 & 124.28 & 50.44 & 2.46 \\
\hline 21 & 26.4 & 31.4 & 40 & 4 & Bauxite & 8420 & 90.25 & 41.1 & 2.2 \\
\hline 22 & 26.4 & 32.1 & 40 & 4 & Bauxite & 8420 & 93.37 & 42.45 & 2.2 \\
\hline 23 & 26.4 & 32.4 & 40 & 4 & Bauxite & 8420 & 107.81 & 53.06 & 2.03 \\
\hline 24 & 26.4 & 31.9 & 40 & 4 & Bauxite & 8420 & 108.33 & 55.36 & 1.96 \\
\hline 25 & 48.4 & 53.1 & 30 & 4 & Bauxite & 6400 & 98.08 & 51.79 & 1.89 \\
\hline 26 & 48.4 & 51.7 & 30 & 4 & Bauxite & 9810 & 103.49 & 58.04 & 1.78 \\
\hline 27 & 55.4 & 43.8 & 40 & 17 & Bauxite & 2100 & 107.86 & 63.86 & 1.69 \\
\hline 28 & 55.4 & 44 & 40 & 17 & Bauxite & 2100 & 112.42 & 63.85 & 1.76 \\
\hline 29 & 30.7 & 44.5 & 30 & 51 & Flint & 10510 & 59.14 & 52.73 & 1.12 \\
\hline 30 & 34 & 50.8 & 30 & 51 & Flint & 4291 & 73.12 & 54.51 & 1.34 \\
\hline 31 & 30.2 & 41.7 & 30 & 51 & Bauxite & 3300 & 94.98 & 60.43 & 1.57 \\
\hline 32 & 30.2 & 44.3 & 30 & 51 & Bauxite & 3400 & 72.81 & 54.5 & 1.34 \\
\hline 33 & 30.2 & 44.2 & 30 & 51 & Bauxite & 3400 & 68.93 & 54.32 & 1.27 \\
\hline 34 & 30.2 & 49.4 & 20 & 51 & Bauxite & 2750 & 64.49 & 45.09 & 1.43 \\
\hline 35 & 30.2 & 45.1 & 20 & 51 & Bauxite & 2750 & 64.14 & 37.95 & 1.69 \\
\hline 36 & 44 & 58.6 & 30 & 9 & Bauxite & 1300 & 74.62 & 60.83 & 1.23 \\
\hline 37 & 44 & 58.6 & 30 & 9 & Bauxite & 1300 & 72.79 & 55.66 & 1.31 \\
\hline 38 & 44 & 55.8 & 30 & 9 & Bauxite & 1300 & 101.45 & 66.22 & 1.53 \\
\hline 39 & 44 & 55.3 & 30 & 9 & Bauxite & 1300 & 59.5 & 55.74 & 1.07 \\
\hline 40 & 36.8 & 47 & 40 & 39 & Bauxite & 15500 & 88.41 & 58.68 & 1.51 \\
\hline 41 & 36.8 & 46.3 & 40 & 39 & Bauxite & 15500 & 88.32 & 66.57 & 1.33 \\
\hline
\end{tabular}


Table 3. Multivariate Analysis Results

\begin{tabular}{|c|c|c|c|c|c|c|}
\hline \multirow{2}{*}{ Variables } & \multicolumn{2}{|c|}{ FN Ratio } & \multicolumn{2}{|c|}{ FN HFST } & \multicolumn{2}{|c|}{ FN Non-HFST } \\
\hline & Coefficients & P-value & Coefficients & P-value & Coefficients & P-value \\
\hline \multicolumn{7}{|c|}{ Considering All Five Independent Factors } \\
\hline Intercept & 3.113 & 0.000 & 146.258 & 0.000 & 40.368 & 0.012 \\
\hline $\begin{array}{l}\text { Precipitation } \\
\text { (Inch) } \\
\text { Average }\end{array}$ & 0.016 & 0.074 & 1.027 & 0.020 & -0.210 & 0.495 \\
\hline $\begin{array}{c}\text { Temperature } \\
\left({ }^{\circ} \mathrm{F}\right)\end{array}$ & -0.037 & 0.003 & -1.626 & 0.005 & 0.459 & 0.250 \\
\hline $\begin{array}{l}\text { Installation } \\
\text { Age (Month) }\end{array}$ & -0.011 & 0.000 & -0.473 & 0.001 & 0.061 & 0.523 \\
\hline Aggregate & 0.064 & 0.684 & 1.978 & 0.791 & -1.517 & 0.780 \\
\hline AADT & 0.000 & 0.265 & 0.000 & 0.462 & 0.000 & 0.619 \\
\hline \multicolumn{7}{|c|}{ Considering only the Two Independent Factors that have Significant Influence } \\
\hline $\begin{array}{l}\text { Intercept } \\
\text { Average }\end{array}$ & 2.912 & $2.62 \mathrm{E}-10$ & 130.027 & $2.07 \mathrm{E}-09$ & 42.056 & 0.000 \\
\hline $\begin{array}{c}\text { Temperature } \\
\left({ }^{\circ} \mathrm{F}\right)\end{array}$ & -0.019 & 0.006 & -0.507 & 0.111 & 0.229 & 0.272 \\
\hline $\begin{array}{l}\text { Installation } \\
\text { Age (Month) }\end{array}$ & -0.013 & $1.05 \mathrm{E}-07$ & -0.575 & 4.07E-07 & 0.094 & 0.141 \\
\hline
\end{tabular}




\section{LIST OF FIGURES}

FIG. 1. HFST Sites

FIG. 2. Example Friction Data

FIG. 3. Example MPD Data

FIG. 4. Average Friction Numbers and MPDs for HFST Sites

FIG. 5. Average Rutting for HFST Sites

FIG. 6. HFST Friction Performance vs. Installation Age and Average Temperature

FIG. 7. HFST Friction Performance vs. Aggregate Type

FIG. 8. HFST Friction Performance Prediction 


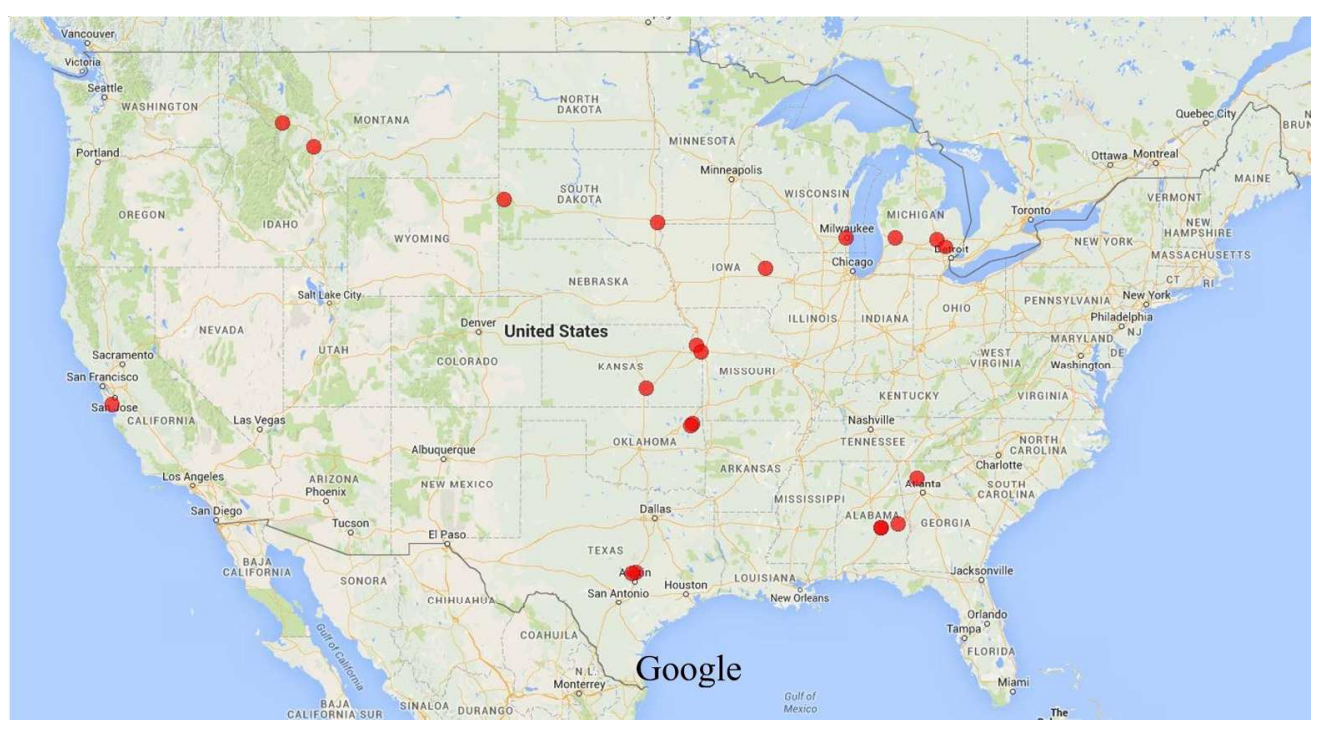

$175 \times 95 \mathrm{~mm}(300 \times 300$ DPI $)$ 


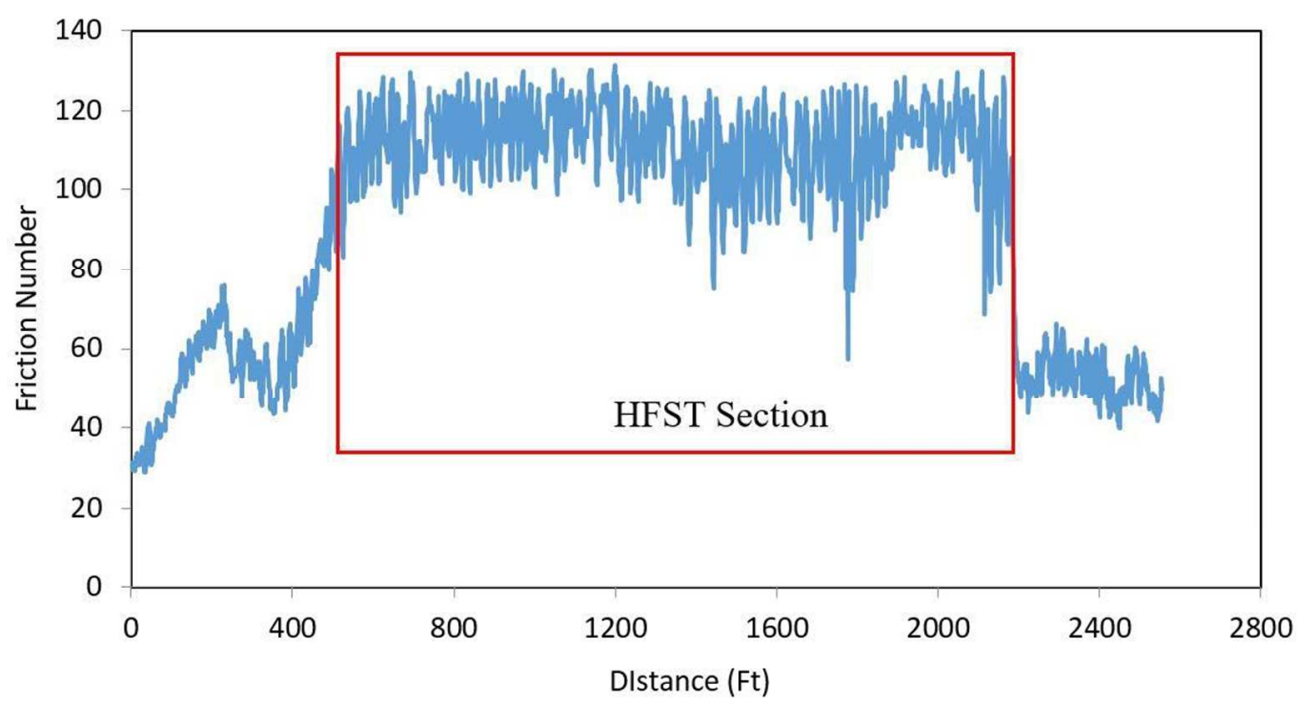

(a) With Distinct Difference

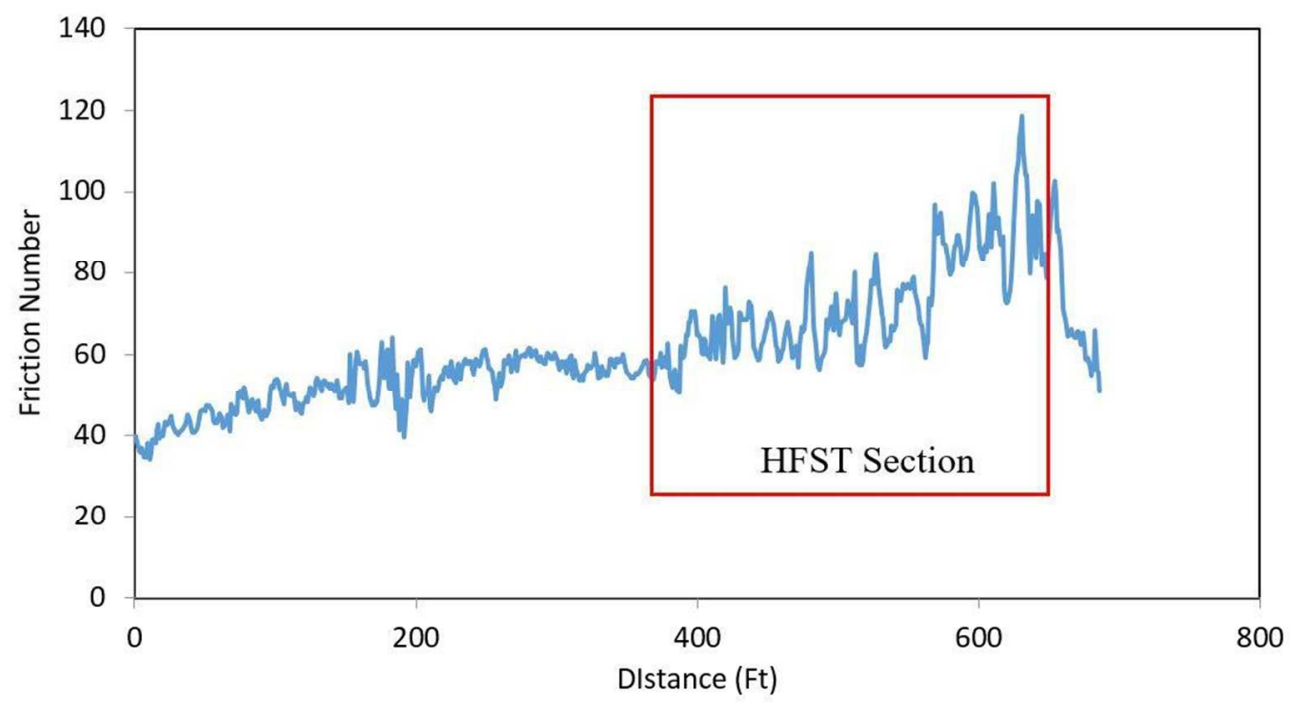

(b) With Minor Difference

$93 \times 111 \mathrm{~mm}(300 \times 300 \mathrm{DPI})$ 


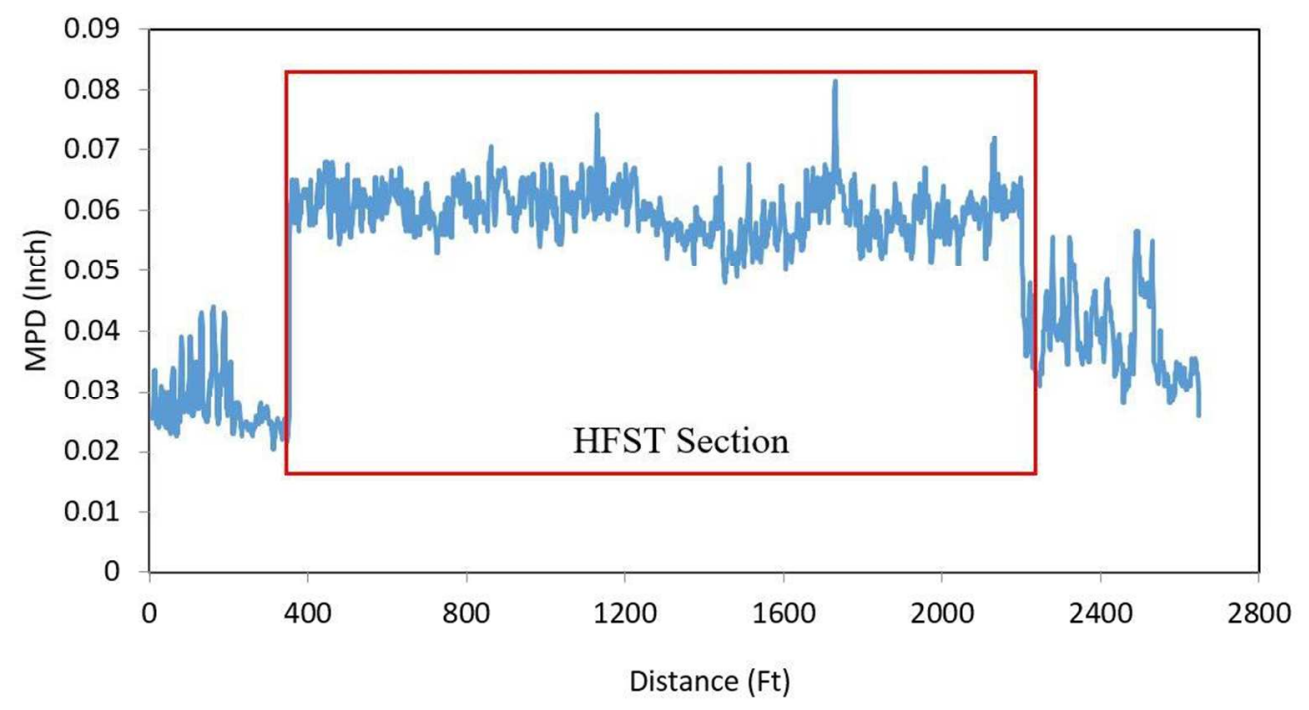

(a) With Distinct Difference

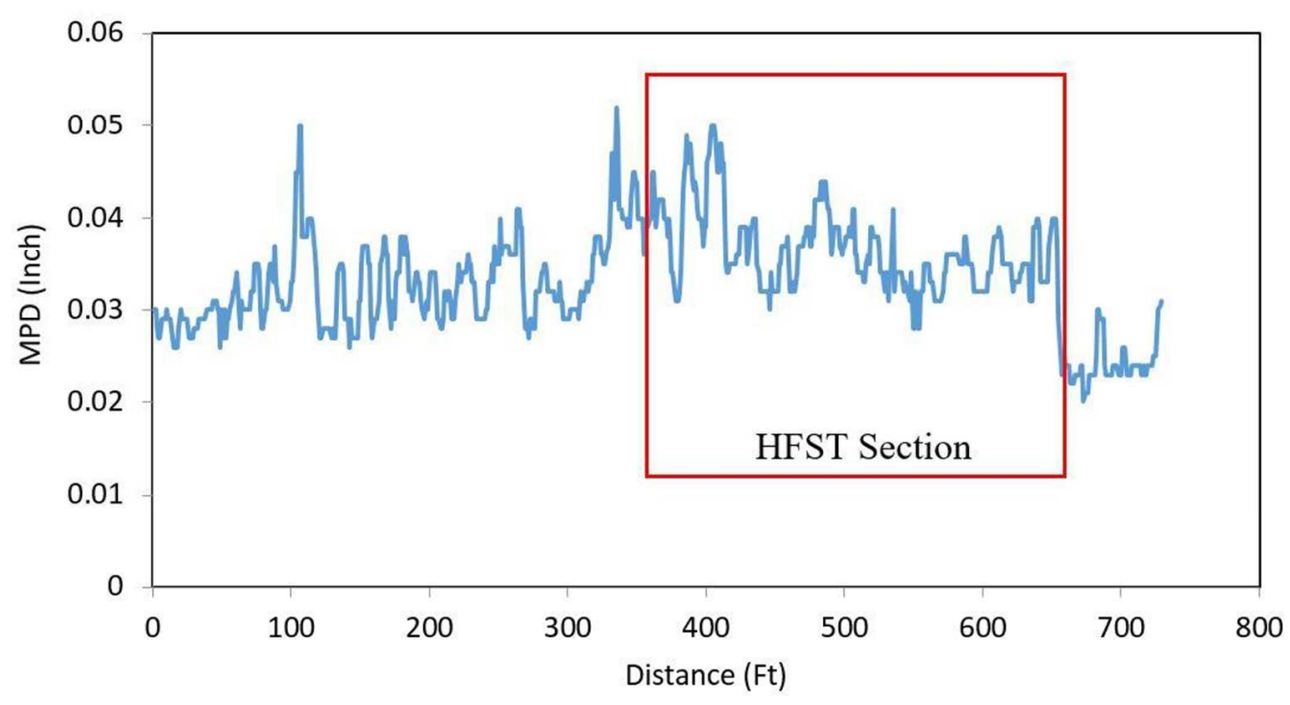

(b) With Minor Difference

$91 \times 111 \mathrm{~mm}(300 \times 300 \mathrm{DPI})$ 

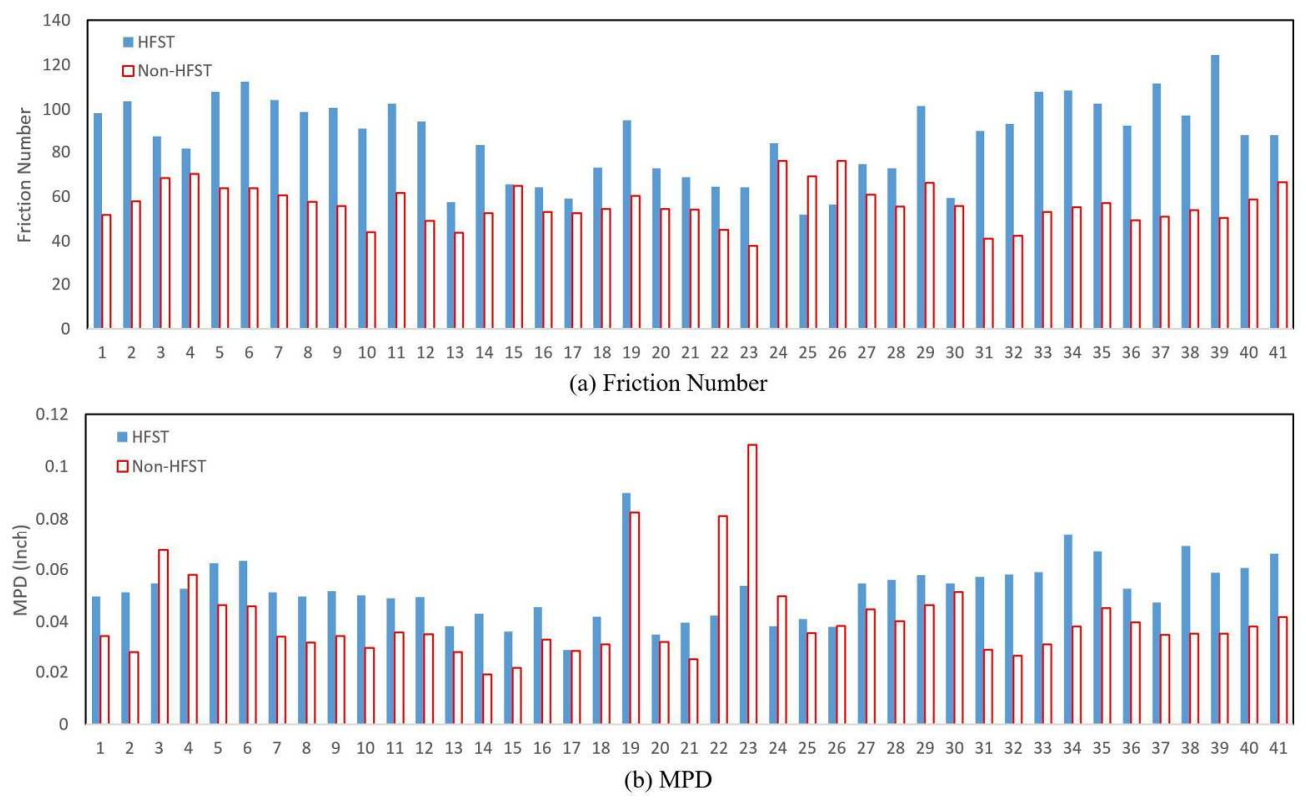

$186 \times 113 \mathrm{~mm}(300 \times 300 \mathrm{DPI})$ 


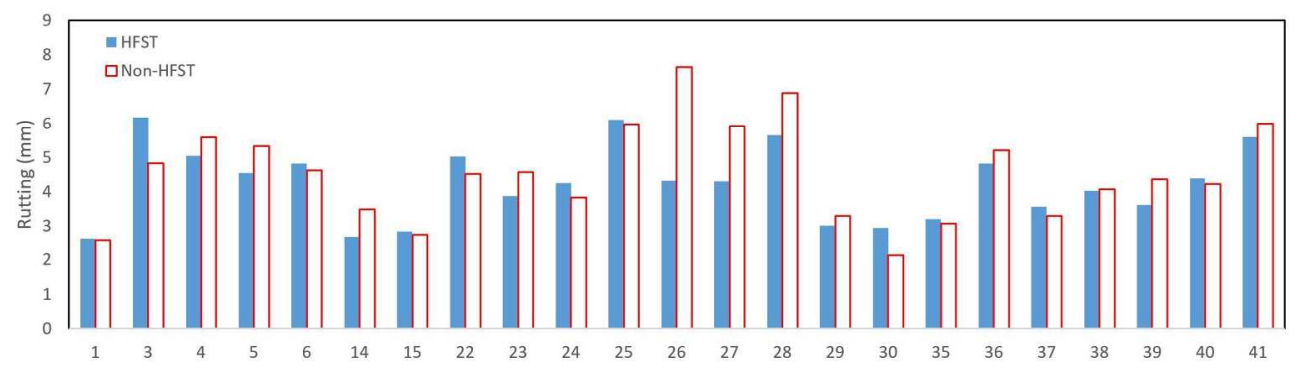

$186 \times 51 \mathrm{~mm}(300 \times 300 \mathrm{DPI})$ 

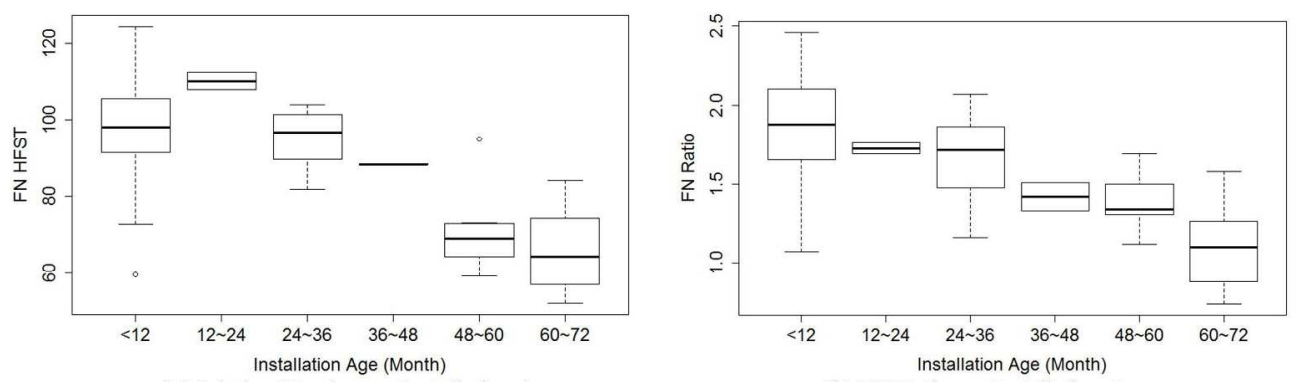

(a) Friction Number vs. Installation Age

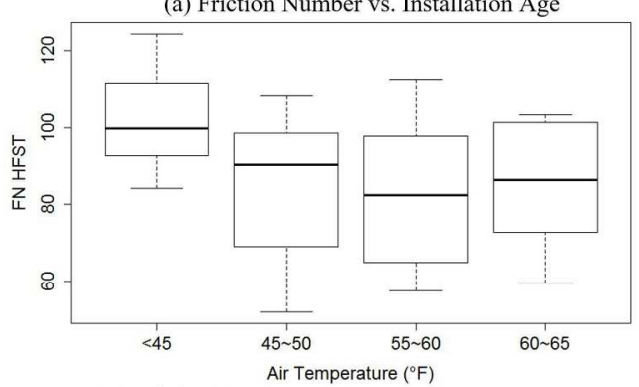

(b) FN Ratio vs. Installation Age

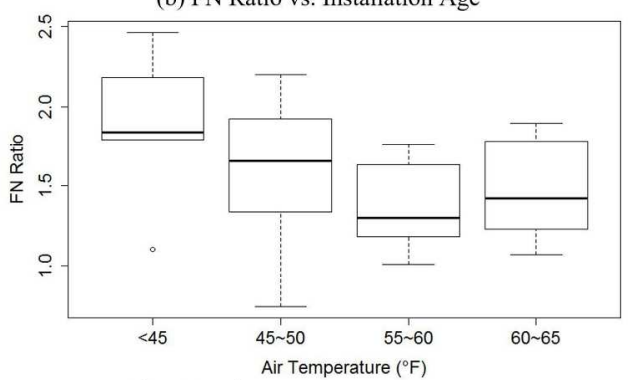

(d) FN Ratio vs. Average Temperature

$186 \times 114 \mathrm{~mm}(300 \times 300 \mathrm{DPI})$ 


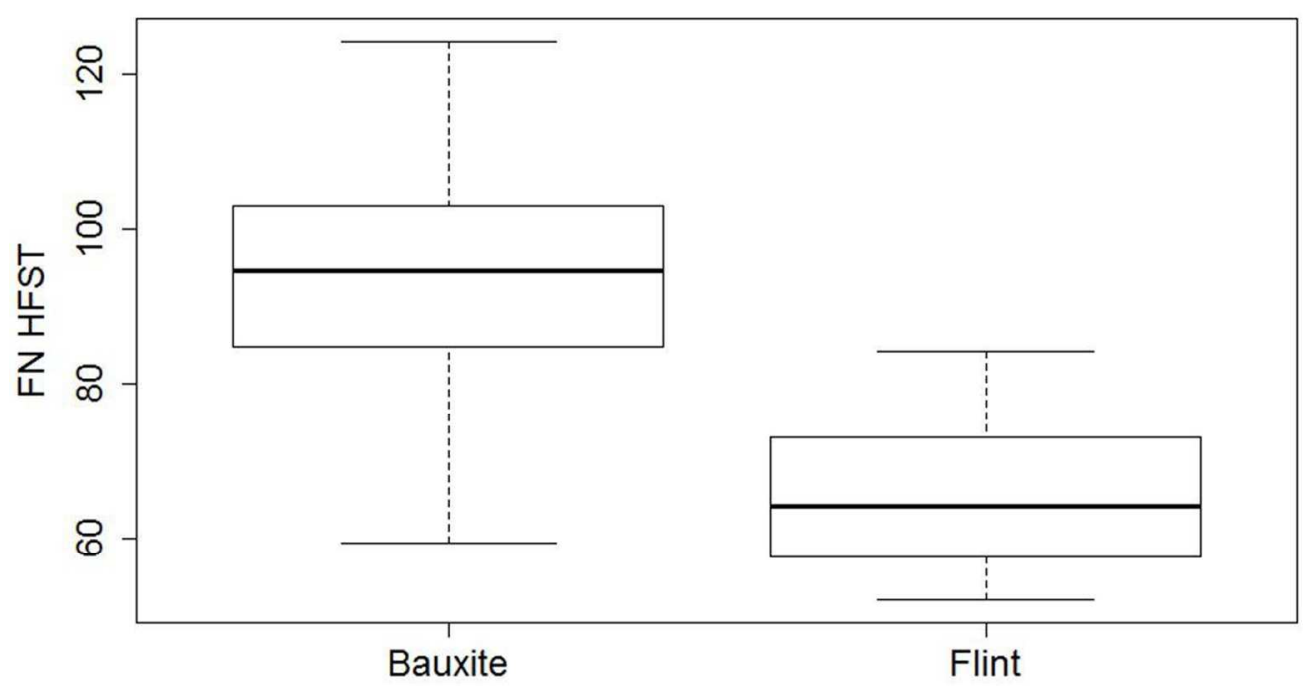

(a) FN $\mathrm{N}_{\mathrm{HFST}}$ Vs. Aggregate Type

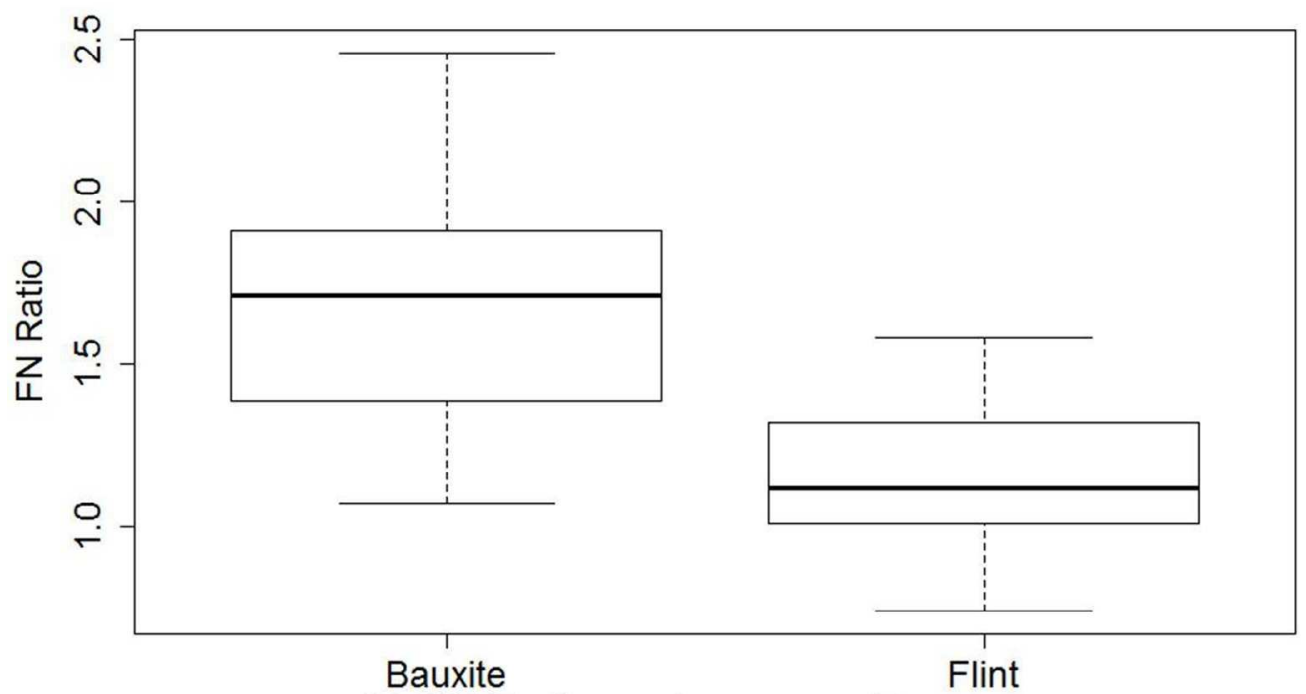

(b) FN Ratio vs. Aggregate Type

$98 \times 115 \mathrm{~mm}(300 \times 300$ DPI $)$ 

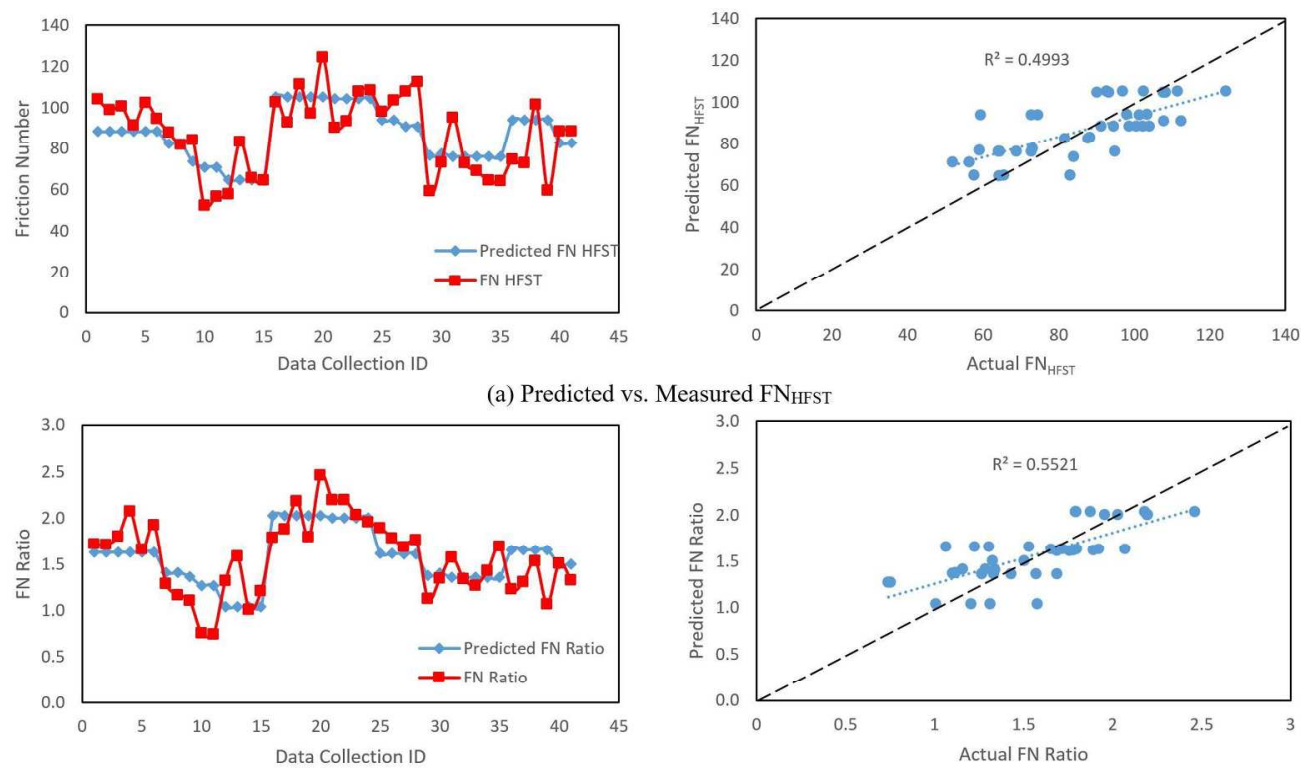

(B) Predicted vs. Measured FN Ratio

$184 \times 114 \mathrm{~mm}(300 \times 300 \mathrm{DPI})$ 